\title{
Seriously moving on
}

\author{
Susie Sanderson
}

Chair, BDA Executive Board

'The political landscape will inevitably change over the next 12 months.' So begins the briefing by the BDA's Public Affairs team for those of us who worked the political party conferences during the last three weeks. Not a statement which comes as a big surprise but once you start to add to it, it becomes more interesting. Whether we'll see a Conservative Government, a hung Parliament with parties sharing power, or a strong enough recovery by Labour to see them hold on to power, only time will tell. If the Conservatives do win a majority, even if it of only one MP, already-announced retirements mean that half of their MPs will be new. Whatever the result, in the pre-election year, it is an unmissable opportunity to influence a large and receptive cohort of prospective parliamentary candidates (PPCs) of all parties.

I write this during a brief break at the Conservative Conference. I follow John Milne and Henrik Overgaard-Nielsen at the Labour and Lib Dem conferences in lobbying MPs and PPCs, seizing spontaneous opportunities to catch big, overtly influential politicians and speaking at fringe events. There aren't many brief breaks - PPCs with real opportunities in the election are fiercely chased but the BDA's extremely professional team, John Hilsdon and Laura Brandon, are equally expert in their preparation and amazing ability to lure likely candidates into our lair. Laura's towel has been on the metaphorical sunbed each morning in the conference hotel, securing a place to talk and offer coffee, earlier than many politicians are on the prowl.

\section{DENTISTRY AS AN ISSUE TO BE TAKEN SERIOUSLY}

The BDA is a member of the Health Hotel - a lobbying group of 45 high-profile organisations with strong health policy interests working together to raise top health issues. Consequently we have excellent access to significant players of the main political parties. John, Henrik and I have shared stages in panel discussions with senior members of the health teams, put our oars in during consultation events and reinforced dentistry as an issue to be taken seriously. The BDA is also the elected secretariat to the All-Party Parliamentary Group for Dentistry and we've been promoting the Group's work and encouraging current and prospective Parliamentarians to engage with it.

More than two years of constant pressure and lobbying is paying off because dentistry is certainly being taken seriously. The Shadow Secretary of State in his speech to conference led on dental services and he and Mike Penning, Shadow Minister for Health, have reminded me of that several times in the last couple of days. Conversations here are fascinating. It is a two way process: I want politicians to hear what the profession has to say but I listen as well. It takes a few seconds to establish the issues of the constituency postbag, a bit longer to establish levels of knowledge and longer to sell our points. Very few discussions follow the same path although recurrent themes emerge in relation to their postbags. The Conservatives have already published their vision for dentistry. The health team has declared in its overall policy that getting rid of targets and working towards outcomes is a priority; prevention is a key, err... target, as is the concentration on public health. No big bangs are planned for any area in health in the worlds of providers, managers or commissioners. Correctly, it is considered that obsession with reconfiguration creates black holes in knowledge, progress, quality improvement and service provision.

\section{RISK OF STEELE ABANDONMENT}

I arrived in Manchester shortly after the General Dental Practice Committee delivered two major messages: not only universal concern about the contractual proposals of the Warburton access team with agreement that the BDA is right to warn members not to sign contracts in their current form, but also a contrasting approval of the recommendations of Professor Jimmy Steele to pilot and evaluate thoroughly his proposals for reform of the delivery of NHS dentistry. One anxiety about the potential for a change of government and the already well worked up policies of the Tory health team is the risk of abandonment of the Steele piloting project. The two are not mutually exclusive though and our suggestions that policies can map quite well across to Steele and that the opportunities must continue to be explored receive a sympathetic audience. Equally, complex conversations about targets and outcomes have given us a chance to describe current contracting challenges.

And while I've listened, MPs and PPCs have related difficulties that their constituents report in understanding the basis on which they receive dental services. Generally there is an appreciation of the challenges and sympathy for dentists working in a deeply flawed contract, but confusion about charges and entitlement sometimes overtakes the issues of inconsistency of commissioning teams and PCTs' placement of dentistry in their priorities.

The last possible date for the General Election is 3 June 2010. The next party conference season will surely have a completely different atmosphere.

DOI: $10.1038 /$ sj.bdj.2009.933 